\title{
Evaluation of accuracy of shade selection using two spectrophotometer systems: Vita Easyshade and Degudent Shadepilot
}

\author{
Mohammad Hassan Kalantari ${ }^{1}$, Seyed Ahmad Ghoraishian ${ }^{1}$, Mina Mohaghegh ${ }^{1}$
}

Correspondence: Dr. Seyed Ahmad Ghoreishian

Email: ahmadg3@yahoo.com

\author{
'Department of Prosthodontics, School of \\ Dentistry, Shiraz University of Medical Sciences, \\ Shiraz, Iran
}

\section{ABSTRACT}

Objective: The aim of this in vitro study was to evaluate the accuracy of shade matching using two spectrophotometric devices. Materials and Methods: Thirteen patients who require a full coverage restoration for one of their maxillary central incisors were selected while the adjacent central incisor was intact. 3 same frameworks were constructed for each tooth using computer-aided design and computer-aided manufacturing technology. Shade matching was performed using Vita Easyshade spectrophotometer, Shadepilot spectrophotometer, and Vitapan classical shade guide for the first, second, and third crown subsequently. After application, firing, and glazing of the porcelain, the color was evaluated and scored by five inspectors. Results: Both spectrophotometric systems showed significantly better results than visual method $(P<0.05)$ while there were no significant differences between Vita Easyshade and Shadepilot spectrophotometers $(P<0.05)$. Conclusion: Spectrophotometers are a good substitute for visual color selection methods.

Key words: Shade guides, shade selection, spectrophotometers

\section{INTRODUCTION}

The increased emphasis on dental esthetics in recent years has developed the need for accurate color replication methods. ${ }^{[1]}$ Any error in reconstruction of teeth color can lead to patient dissatisfaction and failure of the treatment. Studies showed that $80 \%$ of the patients are dissatisfied with color differences between their restoration and adjacent teeth. ${ }^{[2,3]}$ Therefore, precise shade selection and replication are critical in having successful restorations.

Visual and instrumental methods are two ways to assess tooth color. ${ }^{[4]}$ In the visual method, which is still the most popular method for dentists, the color is selected by comparing tooth color with shade tabs

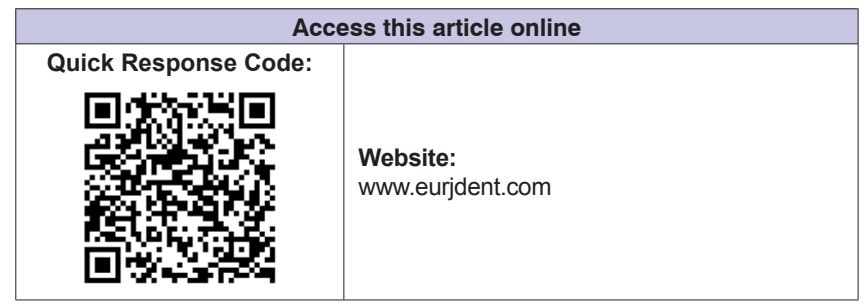

made by different manufacturers and choosing the closest color to the tooth. Two possible limitations are investigated in this method. First, errors by dentist in shade selection, and second, shortcomings inherent in shade tabs. ${ }^{[5]}$ Factors affecting human perception of color, such as fatigue, aging, emotions, physiologic problems, environmental light conditions, and metamerism, can cause problem in visual shade selection. Several factors including surface texture, translucency, and the color of surrounding environment make shade selection for natural teeth more difficult. ${ }^{[5-10]}$ Another shortcoming of the visual

This is an open access article distributed under the terms of the Creative Commons Attribution-NonCommercial-ShareAlike 3.0 License, which allows others to remix, tweak, and build upon the work non-commercially, as long as the author is credited and the new creations are licensed under the identical terms.

For reprints contact: reprints@medknow.com

How to cite this article: Kalantari MH, Ghoraishian SA, Mohaghegh M.
Evaluation of accuracy of shade selection using two spectrophotometer
systems: Vita Easyshade and Degudent Shadepilot. Eur J Dent
2017;11:196-200.
DOI: $10.4103 /$ ejd.ejd_195_16


method is that shade tabs do not cover all colors present in natural teeth. ${ }^{[11]}$

Increasing public demand for cosmetic dentistry results in the progress of color determining instruments. In recent years, several electronic shade-matching devices such as spectrophotometers and colorimeters have been available for dental use. ${ }^{[12]}$

Spectrophotometers are among the most accurate, useful, and flexible instruments for color matching. ${ }^{[13]}$ A spectrophotometer functions by measuring the spectral reflectance or transmittance curve of a specimen. ${ }^{[14,15]}$ They are useful in the measurement of surface color. ${ }^{[12]}$ A prism disperses white light from a tungsten filament bulb in the spectrophotometer into a spectrum of wavelength bands between 5 and $20 \mathrm{~nm}$. The amount of light reflected from a specimen is measured for each wavelength in the visible spectrum. Spectrophotometers have a longer working life than colorimeters and are unaffected by object metamerism. ${ }^{[12,16]}$

The reliability and accuracy of these instruments in precise shade matching are questionable. There are several studies, which compare the visual and instrumental color matching methods, but the findings are controversial because of using different instruments or different methods of comparing. In 2008, Da Silva et al. compared Easyshade spectrophotometer with three visual shade guide systems. They concluded that crowns fabricated using a spectrophotometer showed a significantly better color match and a lower rate of rejection due to shade mismatching. ${ }^{[17]}$ There are several other studies supporting instrumental methods in comparison with visual ones. ${ }^{[6,18,19]}$ In contrast with Da Silva et al., Yilmaz and Karaagaclioglu ${ }^{[20]}$ show that visual method is more accurate than instrumental method.

The purpose of this study was to evaluate the accuracy of color measurements of two dental electronic shade-matching devices against the visual method.

The null hypothesis for this study was composed of two different parts: (1) Color analysis by means of a spectrophotometer device will improve color matching in comparison with visual method and (2) different spectrophotometer devices show different shade matching results.

\section{MATERIALS AND METHODS}

Thirteen patients who required a full coverage restoration in one of their central incisors were entered into the study. The presence of an intact central incisor with a contralateral incisor in need of a complete coverage restoration was the primary inclusion criteria. The exclusion criteria were the presence of any decay, restoration, or any sign of current or previous periodontal disease in the adjacent teeth. Three metal ceramic crowns were fabricated for each patient. The first was fabricated using visual shade matching, while the other two were fabricated using two different spectrophotometers. The color match of each crown was analyzed.

After providing written consent, preliminary impression from upper and lower arches was made using stock tray and irreversible hydrocolloid (Zhermack, Badia Polesine, Italy). The casts were poured using Type IV dental stone (elite rock; Badia Polesine, Zhermack Rovigo, Italy). Interocclusal wax records were used to mount the casts in an articulator. A study wax-up was performed, and preparation indices were made using condensational silicon material (speedex; coltane, Alstatten, Switzerland). The selected tooth was prepared for metal ceramic restoration with a 1 $\mathrm{mm}$ wide 135-shoulder finish line and $0.5 \mathrm{~mm}$ beneath gingival margin. Definitive impressions were made using additional silicone material (putty and wash) (Elite HD, Zhermack, Badia Polesine, Italy) and a stock tray. Provisional restoration was fabricated using Tempron (GC America, Alsip, IL, USA) and luted with provisional cement (TempBond, Kerr Corp., Orange, CA, USA). The impression was poured with Type V dental stone (elite rock; Badia Polesine, Zhermack Rovigo, Italy). The poured cast was scanned using a 3D-laser scanner (3 shapeD810, 3shape, Copenhagen $\mathrm{K}$, Denmark). The data were transferred to CAD Software (3 Shape's CAD Design Software, 3shape, Copenhagen K, Denmark) in which the frameworks were designed. 3 exactly same metal frameworks were then waxed-up using CAM machine (450 CAD/CAM, Imes-icore, $\mathrm{GmbH}$, Eiterfeld, Germany) for each tooth. The wax patterns then casted using induction casting machine (Degudent, Hanau, Germany) with base metal alloy (For all, Ivoclar Vivadent, Schaan, Liechtenstein).

\section{Color selection and porcelain application}

Three Crowns were made for each tooth. One crown was fabricated based on visual shade matching by Vitapan classical shade guide (VITA Zahnfabrik, Bad Sackingen, Germany). Two commercially available electronic shade-matching devices were used for the other two crowns: Vita Easyshade and Degudent Shadepilot [Table 1]. Both devices were operated according to manufacturer's instructions. 
VITA Easyshade was calibrated by placing a probe tip on the calibration port aperture before each specimen measurement. The targets were measured by holding the probe tip at 90 degrees on the surface of the teeth. According to the manufacturer's instructions, the measurement was accepted when two consecutive, identical readings were generated for each area.

After Degudent Shadepilot was calibrated, the device was put in the triple-zone measurement mode. The targets were measured by placing the device mouthpiece at right angle to the labial surface of the patient's tooth. Again, the measurement was accepted when 2 consecutive, identical readings were generated for each area.

A single skilled dental technician with 15-year experience did all shade selections. The technician was first screened for defective color vision using a color discrimination test (Neitz test of color vision, western physiological services, Los Angeles, CA, USA). All shade selections were done under D65 light source (judge2; GretagMacbeth, Grand Rapids, MI, USA), between 10 and 12 am while the patients were positioned on dental chair so that his/her mouth was at the same level and $40 \mathrm{~cm}$ apart from observers' eyes. Shade selections were done in 3 areas of the tooth (incisal, middle, and cervical third) [Figure 1].

Porcelain (Vita VM9; Ivoclar Vivadent, Liechtenstein, Germany) applications and firing cycles were done by a skilled technician due to the current standards of metal ceramic crown fabrication. Each crown was positioned on the patient's tooth, and the color was evaluated visually. Finished crowns were then glazed and send to the clinic for evaluation.

\section{Crowns evaluation}

Each crown was seated on the tooth, and then, its color match with adjacent sound tooth was evaluated [Figure 2]. The evaluations were done by five prosthodontists who do not have any color discrimination disorders.

Each examiner was said to choose a score for color similarity of crown and adjacent tooth on a scale

\begin{tabular}{lll}
\multicolumn{2}{l}{ Table 1: Devices evaluated } \\
\hline Device & Manufacturer & Type \\
\hline Vita Easyshade & VITA Zahnfabrik, Bad & Spectrophotometer \\
& Sackingen, Germany & \\
Shadepilot & Degudent, Hanau, Germany & Spectrophotometer \\
\hline
\end{tabular}

of $1-10$, with 10 as a perfect match; 1 as no match; $\geq 7$, accepted; $<7$, rejected. The final acceptance or rejection decision was based on the mean score of the 5 examiners. Finally, a chart was completed for each crown by mean of scores by 5 examiners. Examiners did not know the method of crown fabrication.

\section{Statistical analysis}

The means for different groups were compared using Wilcoxon test. All statistical analyses were performed using SPSS 16.0 for Windows (SPSS 16.0 for Windows; SPSS Inc., Chicago, IL, USA).

\section{RESULTS}

About $7.6 \%$ of crowns fabricated by conventional method (1 out of 13) were deemed acceptable by evaluators. By contrast, $73 \%$ of spectrophotometric crowns (19 out of 26) were deemed acceptable. Table 1 shows the means and standard deviations (SDs) of scores of examiners for each group.

Table 2 shows the means and SDs of scores of examiners for each group: (1) Easyshade spectrophotometer. (2) Shadepilot spectrophotometer. (3) Vitapan classical shade guide (no of specimen $=13$ ).

a. Comparison of first and third groups by Wilcoxon test showed a significant difference between them $(P=0.008)$ with the first group showing significantly better results, so using Easyshade spectrophotometer can improve color matching in comparison with visual method

b. Comparison of second and third groups revealed a significant difference between them $(P=0.034)$ with the second group showing better results.

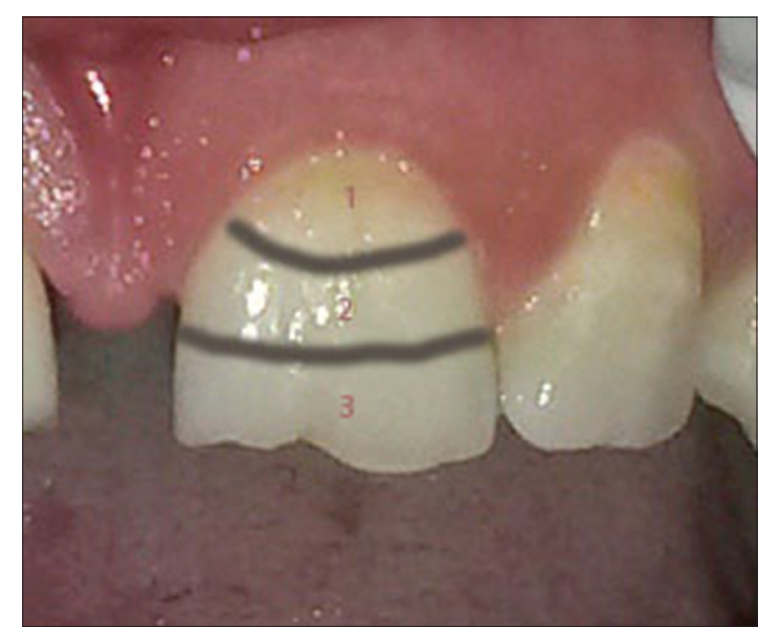

Figure 1: Triple-zone measurement. Shade selections were done in three areas of the tooth (incisal, middle, and cervical third) 


\begin{tabular}{|c|c|c|c|}
\hline Devices & Mean & SD & SEM \\
\hline Vita Easyshade & 7.2154 & 0.83850 & 0.23258 \\
\hline Shadepilot & 7.3077 & 1.37020 & 0.38002 \\
\hline Vitapan classical & 6.3077 & 0.37961 & 0.10528 \\
\hline
\end{tabular}

These findings suggest that using Shadepilot spectrophotometer can improve color matching in comparison with visual method

c. Comparison of the first and second groups showed no significant differences $(P=0.844)$ between them, revealing no significant differences between Easyshade and Shadepilot spectrophotometers.

\section{DISCUSSION}

The results of this study strongly support the acceptation of the first part of null hypothesis since there was a significant improvement in color matching by means of spectrophotometer in comparison with visual color determination method. However, no significant difference was observed between the two spectrophotometers. Thus, the data do support rejection of second part of null hypothesis.

In 2008, Da Silva et al. ${ }^{[17]}$ compared visual and instrumental shade matching methods. They found color matching by spectrophotometer more reliable than visual method. They said that it can also significantly reduce the unacceptable results. In this study, better results achieved by spectrophotometer device, but the only unacceptable result was in Easyshade spectrophotometer group.

In 2002, Paul et al ${ }^{[6]}$ compared visual color matching method using Vitapan classical shade guide with spectroshade spectrophotometer. They also achieved better results for spectrophotometer group. They claimed that using a device rather than human vision is a good substitute for color matching. In this study, the crowns made using a spectrophotometer were preferred in $90 \%$ of cases rather than the crowns made by visual method. However, in our study, Easyshade spectrophotometer showed better results in $85 \%$ of cases, and Shadepilot spectrophotometer acted better in $70 \%$ of cases.

In Paul et al., Da Silva et al., and our studies better results were achieved in color matching when using a device.

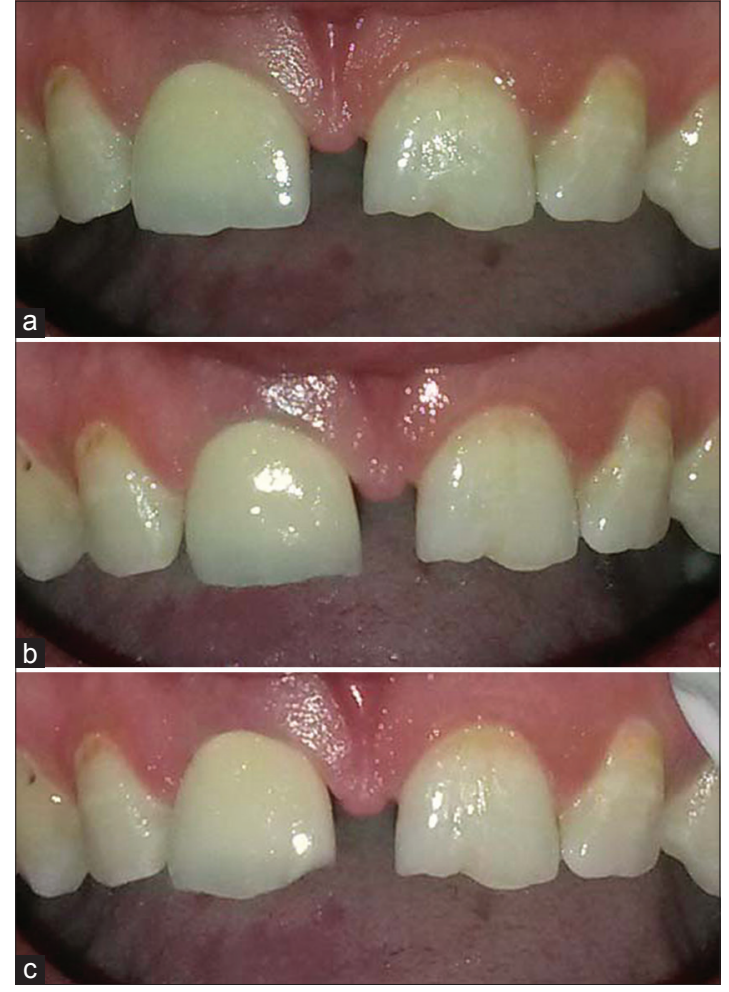

Figure 2: (a) Clinical evaluation of restoration fabricated by Vita Easyshade shade matching. (b) Clinical evaluation of restoration fabricated by Shadepilot shade matching. (c) Clinical evaluation of restoration fabricated by Vitapan classical shade matching

One of the causes which can affect these results is a so-called "Hawthorne effect" in which when color determination data are achieved from a spectrophotometer device, more effort is done for color matching by the technician. ${ }^{[17]}$

This limitation was seen in both Da Silva et al. and our study although Paul et al., served the technician only the color not the way it was achieved.

In contrary, $\mathrm{Li}$ and Wang ${ }^{[18]}$ compared visual color matching method using Vintage Halo shade guide and instrumental method using Shade Eye calorimeter (shade eye, Shofa, Japan) in 2007. They reported that none of these methods showed excellent color matching and there was no significant difference between them. The reason they reached different results with our study can be because they used different shade guide and device than our study.

This study was not free of limitations. Some of these limitations are discussed as follows. First, the specimens were produced and tested under the ideal conditions, which may not reflect actual clinical conditions. Second, the ease of use and degree of 
technique sensitivity were not evaluated in this study, which are important factors in clinical conditions. Third, the presence of metal framework beneath the porcelain can affect the acceptability of color reproduction. It is recommended that future studies on color matching take place on full ceramic crowns rather than metal ceramic. Finally, we used Vitapan classical shade guide for visual color matching due to its popularity and wide use by dentists. It is also suggested that future studies take place on 3D-Master shade guide.

\section{CONCLUSION}

Within the limitations of this study, following conclusions were drawn:

1. The acceptance/rejection ratio of the crowns fabricated by spectrophotometric method was significantly higher than the crowns fabricated by conventional method

2. There was no significant difference between color matching results of Easyshade and Shadepilot spectrophotometers.

\section{Acknowledgments}

The authors would like to thank the Vice-Chancellery of Shiraz University of Medical Sciences for supporting this research study (Grant\#4601). The article is based on a thesis by Dr. Ahmad Ghoreishian. The authors also thank Dr. Vosough from the Dental Research Development Center, School of Dentistry for his contributions in the process of statistical analysis.

\section{Financial support and sponsorship} Nil.

\section{Conflicts of interest}

There are no conflicts of interest.

\section{REFERENCES}

1. Mayekar SM. Shades of a color. Illusion or reality? Dent Clin North Am 2001;45:155-72, vii.

2. Elamin HO, Abubakr NH, Ibrahim YE. Identifying the tooth shade in group of patients using Vita Easyshade. Eur J Dent 2015;9:213-7.

3. Baldwin DC. Appearance and aesthetics in oral health. Community Dent Oral Epidemiol 1980;8:244-56.

4. Okubo SR, Kanawati A, Richards MW, Childress S. Evaluation of visual and instrument shade matching. J Prosthet Dent 1998;80:642-8.

5. Kim-Pusateri S, Brewer JD, Davis EL, Wee AG. Reliability and accuracy of four dental shade-matching devices. J Prosthet Dent 2009;101:193-9.

6. Paul S, Peter A, Pietrobon N, Hämmerle CH. Visual and spectrophotometric shade analysis of human teeth. J Dent Res 2002;81:578-82

7. King KA, deRijk WG. Variations of $L^{*} a^{*} b^{*}$ values among Vitapan Classical Shade Guides. J Prosthodont 2007;16:352-6.

8. Bayindir F, Kuo S, Johnston WM, Wee AG. Coverage error of three conceptually different shade guide systems to vital unrestored dentition. J Prosthet Dent 2007;98:175-85.

9. Dagg H, O'Connell B, Claffey N, Byrne D, Gorman C. The influence of some different factors on the accuracy of shade selection. J Oral Rehabil 2004;31:900-4.

10. Sproull RC. Color matching in dentistry. Part I. The three-dimensional nature of color 1973. J Prosthet Dent 2001;86:453-7.

11. Brewer JD, Wee A, Seghi R. Advances in color matching. Dent Clin North Am 2004;48:341-58.

12. Berns RS. Billmeyer and Saltzman's Principles of Color Technology. $3^{\text {rd }}$ ed. New York: John Wiley and Sons; 2000. p. 88-92.

13. Paul SJ, Peter A, Rodoni L, Pietrobon N. Conventional visual vs. spectrophotometric shade taking for porcelain-fused-to-metal crowns: A clinical comparison. Int J Periodontics Restorative Dent 2004;24:222-31

14. Khurana R, Tredwin CJ, Weisbloom M, Moles DR. A clinical evaluation of the individual repeatability of three commercially available colour measuring devices. Br Dent J 2007;203:675-80.

15. Jain C, Bhargava A, Gupta S, Rath R, Nagpal A, Kumar P. Spectrophotometric evaluation of the color changes of different feldspathic porcelains after exposure to commonly consumed beverages. Eur J Dent 2013;7:172-80.

16. Paravina RD, Powers JM. Esthetic Color Training in Dentistry. St. Louis: Elsevier; 2004. p. 17-28, 169-70.

17. Da Silva JD, Park SE, Weber HP, Ishikawa-Nagai S. Clinical performance of a newly developed spectrophotometric system on tooth color reproduction. J Prosthet Dent 2008;99:361-8.

18. Li Q, Wang YN. Comparison of shade matching by visual observation and an intraoral dental colorimeter. J Oral Rehabil 2007;34:848-54.

19. Dozic A, Kleverlaan CJ, El-Zohairy A, Feilzer AJ, Khashayar G. Performance of five commercially available tooth color-measuring devices. J Prosthodont 2007;16:93-100.

20. Yilmaz B, Karaagaclioglu L. In vitro evaluation of color replication of metal ceramic specimens using visual and instrumental color determinations. J Prosthet Dent 2011;105:21-7. 